\title{
INTERCALAÇÃO: CONSIDERAÇÕES SOBRE O METATEATRO
}

\author{
João Alfredo Dal Bello \\ Universidade Federal do Paraná
}

O presente espaço pretende ocupar-se com o modelo conhecido como metateatro, um dos possíveis referenciais para investigações nos estudos de dramaturgia. Esta designação de um modo característico de se fazer teatro explica-se, parcialmente, por si mesma: o prefixo grego met(a) indica "mudança", "posteridade", "além", "transcendência", "reflexão crítica sobre", como ensina o dicionário (Ferreira, 1975, p.917). Basicamente, trata-se de um tipo de teatro que transcende a forma convencional desta arte para exercer uma reflexão sobre si mesmo, como forma, e sobre o discurso literário que apresenta. Poderia caber-lhe, por analogia, a explicação de Barthes (1970) para literatura e metalinguagem: "ao mesmo tempo objeto e olhar sobre esse objeto, fala e fala dessa fala". Detenho-me a seguir na apresentação do que entendem por metateatro o dramaturgo e crítico teatral Lionel Abel, e Manfred Schmeling, o primeiro dando ênfase ao estudo teórico; o segundo à questão didática. Adiante ainda será citado o pensamento de Anne Ubersfeld.

Os exemplos arrolados para elucidação privilegiarão Bertolt Brecht, visto ser ele ainda hoje - acatado ou refutado - referencial necessário nos estudos de dramaturgia, e por ser o teatro no teatro uma das formas estruturais mais importantes no seu produtivo trabalho para o palco. Além disso, a própria obra de Abel o traz à cena, provocando no leitor um efeito de muito estranhamento (!) e convocando a uma tomada de posição.

Segundo a concepção de Abel, as metapeças elaboram aquelas figuras que são dramáticas antes mesmo de o dramaturgo notá-las; aquelas que foram dramatizadas, inicialmente, pelo mito, pela lenda, a literatura e a história. Isto quer dizer que uma imaginação anterior à do dramaturgo já exercitara um relacionamento de teatralidade com elas. Ao reabordá-las, na ficção dramatúrgica, tais figuras se apresentam com uma teatralidade inerente. É por isso que se prestam, amiúde, a 
uma construção de peça-dentro-de-outra-peça. Contudo, para Abel, o conceito de metateatro extrapola o recurso simplesmente técnico de teatro-no-teatro. Com o termo metateatro ele designa toda uma gama de obras para o palco, algumas das quais não apresentam uma peçadentro-de-outra-peça nem sequer como recurso técnico. Para ele, peças assim designadas têm uma característica comum: são todas obras teatrais sobre a vida considerada como já teatralizada. Temos, então, construções dramáticas a que se unem dois elementos: o fato já pensado e registrado e o reconhecimento do dramaturgo de que foi sua imaginação que controlou o acontecimento, desde o início até o fím, na estruturação da obra teatral. Adotados tais recursos, tanto o plano da forma como o do conteúdo serão afetados, uma vez que a inserção de novos elementos no fluxo da encenação exigirá que o espectador reflita sobre a razão para tal ruptura e redimensione seu entendimento da proposta da encenação. "Peças do tipo...existem. Não as inventei. Entretanto, terei a ousadia de dar-lhes uma designação. Chamo-as de metapeças, obras de metateatro" (Abel, 1968,p.88). Vejamos algumas características propostas pelo teórico:

[...] metapeça [...] é a forma necessária para a dramatização de personagens que, tendo plena autoconsciência, não podem ser impedidos de participar em sua própria dramatização. Donde a famosa fala de Jaques, o filósofo shakespeariano do metateatro: "o mundo todo é um palco, e todos os homens e mulheres apenas atores." (Abel, op. cit., p. 109)

Entende Abel que é assim também o pensamento de Calderón: haverá na metapeça sempre um componente fantástico,

Pois nesse tipo de peça a fantasia é essencial, é justamente aquilo que vamos encontrar no âmago da realidade. Em verdade podemos dizer que a metapeça está para a fantasia comum assim como a tragédia está para o melodrama. Assim como na tragédia as atribuições do herói têm de ser necessárias, e não acidentais, na metapeça a vida tem de ser um sonho, e o mundo tem de ser um palco. (Abel, op. cit., p.110)

Abel contrapõe o herói da metapeça àquele da tragédia grega. Nesta, o herói é derrotado, e por isto a realidade do mundo é sublinhada; na metapeça, o herói não pode ser definitivamente derrotado, talvez não 
possa mesmo chegar a ser heróico; no entanto, a realidade do mundo é mortalmente afetada: a ilusão se torna inseparável da realidade.

Mais adiante, em novo capítulo, Abel vai relacionar Brecht com o metateatro. De início, contrapõe o escritor de peças a dramaturgos como Ibsen, Hauptmann e Sudermann, interessado que estava em subverter e substituir a dramaturgia burguesa por eles representada, ainda que contrariando os teóricos comunistas do teatro, simpáticos às técnicas realistas e naturalistas de dramaturgia, interpretação e até mesmo cenografia. Privilegiavam um teatro do tipo stanislavskiano, com sua concentração na análise detalhada da motivação individual num ambiente realista. Para aqueles teóricos, o teatro tinha valor enquanto veículo de propaganda; para Brecht, só o teria se fosse expressão de suas convicções.

$\mathrm{Na}$ opinião de Abel, como chegou Brecht ao metateatro? Para justificar seu entendimento, devota o capítulo Brecht: seu não e seu sim à tentativa de comprovar que Brecht realmente queria, por um lado, negar a experiência moral e o indivíduo, não por indiferença, mas motivado pela indignação e o desapontamento diante da descoberta de que, em sua época, a própria idéia do indivíduo europeu estava morrendo, e, por outro, afirmar o corpo humano em seu calor, sua fraqueza, sua suscetibilidade, seus apetites, o corpo humano em seus anseios e em seus pensamentos. Diante da pergunta por que Brecht permaneceu fiel ao comunismo, responde: "Pode ser que ele julgasse que mesmo o comunismo moderno, distorcido, por causa de sua base filosófica no materialismo, era a política do corpo humano e portanto preferível ao liberalismo ocidental, baseado como é no que ele considerava uma falsa afirmação da alma individual." (Abel, op. cit., p.137)

Para comprovar que "o corpo humano é que é herói de todas as obras importantes que Brecht escreveu" após a ensinadela com que o Partido brindou sua peça $A$ medida - pró-comunista demais para os comunistas, e, portanto, também para os anticomunistas -, Abel sustenta que o "corpo humano, em seu desejo de se alimentar, de se sustentar, e de gastar-se a si mesmo é o verdadeiro herói de Mãe Coragem, Puntila, O Círculo de Giz Caucasiano e Galileu" (op. cit., p.129). E conclui: "Creio que Brecht amava o corpo abstrato, o corpo em si, com um sentimento semelhante ao que cada pessoa tem pelo seu próprio corpo. Para fazer o corpo o seu herói, é claro que Brecht 
tinha de fazer uso de um método dramático muito particular e depender de uma forma especial." (Abel, op. cit., p.138)

Essa linha de pensamento vai ser coroada com a observação de que "... a mais extraordinária de todas as celebrações poéticas do corpo feitas por Brecht é sua peça Galileu..." e de que "esta é uma das melhores peças de Brecht, talvez a maior de todas" (op. cit., p.133). De passagem, é possível que Brecht, caso pudesse receber este elogio, não ficaria muito lisonjeado, pois, ao ser lembrado pelo jornalista austríaco Hans Winge de que o próprio autor teria considerado ser Galileu uma obra secundária de pouco significado, Brecht confirma: "quanto à parte formal não defendo esta peça com muita força" (apud Hecht, 1973, p.747).

Tendo definido o metateatro como repousando sobre dois postulados básicos: o mundo é um palco, e a vida é um sonho, Abel entende não ser possível asseverar que Brecht considerasse esses dois postulados como verdades a serem demonstradas em suas obras. Seria mesmo exigir demais do dramaturgo marxista. O que o teórico deseja afirmar é que Brecht, ao rejeitar a significação do indivíduo e da experiência moral, teve de apoiar-se nesses conceitos para dar forma a suas peças. Para justificar o primeiro postulado em Brecht, recorda que ele lançava mão de um recurso favorito: que os atores representassem uma emoção como se estivessem contando a experiência de outra pessoa. Isto é verdadeiro; basta lembrar, como exemplo, as cenas do noivado e do reencontro de Simon e Grusche em $O$ círculo de giz caucasiano, em que o diálogo entre o par ocorre na terceira pessoa, como se estivessem relatando o que se passou com outros. Para Abel, " acreditasse Brecht ou não que o mundo é um palco, suas peças, seus conceitos de interpretação e de cenografia eram todos planejados para produzir tal efeito. A realidade de suas peças é a do teatro e não a da vida, a não ser quando acontece que esta última se torna teatral." (Abel, op. cit., p.141)

Concordo com a afirmação de que a realidade das peças de Brecht é a do teatro. Nesta altura parece-me até supérflua, uma vez sabido o rechaço que votava ao teatro embotador de sentidos e consciência crítica, ou culinário, no dizer irônico do dramaturgo. Não foi por outra razão que ele desenvolveu as técnicas de estranhamento. 
Se a primeira proposição encontra dificuldades em sua aplicação a Brecht, mais dificuldade terá a segunda. Concorda com isto o próprio Abel, dizendo:

Poderia este homem teimoso e prático acreditar que a vida era um sonho? Ainda uma vez creio que ele nunca faria conscientemente tal asserção. Porém, quando não se vê nenhuma necessidade interior na vida das gentes, não parecerão tais vidas um sonho? [...] O pensamento frio e desapaixonado, como o que Brecht sempre advogou e dizia querer induzir em seu público, é precisamente aquele tipo de pensamento que não poderá nunca asseverar a realidade de qualquer pessoa que não seja a que está pensando. A vida, de qualquer forma, tinha de ser um sonho para Brecht, dada a sua desvalorização extrema do sentimento individual. (Abel, op. cit., p.141-142)

A última frase da citação provoca-me a impressão de que em Abel a leitura de Brecht se deu de forma fragmentária ou direcionada. É verdade que, pela ótica marxista, a pretensão individualista se desmerece; o que conta é o interesse coletivo. No entanto, afirmar que o sentimento individual seja desvalorizado por Brecht ao extremo equivale a admitir desinformação e lacuna no conhecimento de sua obra. O que pleiteava o dramaturgo alemão é que o indivíduo submetesse seus sentimentos a um exame crítico e, então, os colocasse a serviço da coletividade. Não é outro o sentido do que se resume ao final de $O$ círculo de giz caucasiano:

E vocês, que escutaram bem a história do círculo de giz, Escutem sempre com todo o respeito

o que um mais velho diz:

as coisas devem antes pertencer

a quem cuidar bem delas,

as crianças às mulheres mais ternas

para crescerem belas,

a carruagem ao melhor cocheiro

para bem viajar, 
e o vale aos que o souberem irrigar para bons frutos dar. (Brecht, 1992, v. 9, p.296)

Ocorre-me a tentação de associar a proposição de Abel, de que a vida é sonho, ao sonho da utopia socialista de Brecht, mas, na leitura subsequiente do estudo, vejo-me desautorizado a desenvolver tal raciocínio, porquanto aquele autor insiste que "o espectador formará tal noção ou sentirá seu sugestionamento como resultado do efeito da peça" (Abel, op. cit., p.142). A noção de vida como sonho a que Abel se refere - e coloca Brecht junto com Shaw, Pirandello, Beckett e Genet - exclui a intenção doutrinária das peças do dramaturgo alemão. É verdade que Brecht queixou-se da recepção de algumas das peças - Mãe Coragem e seus filhos, por exemplo - junto ao público burguês; contudo, seria ousado demais negar-lhes a premissa ideológica e a intenção proselitista. Mais cordato seria afirmar que certa parte dos espectadores poderia inferir das peças brechtianas que a vida é sonho.

Tudo somado, o que se extrai de Abel sobre o metateatro em Brecht é pouco e de frágil sustentação. Atribuo-lhe crédito por tentar associar o escritor de peças a esta forma, o que pretendo evidenciar adiante. O mais consistente na obra do pensador é a proposta de uma leitura de obras dramatúrgicas pelas lentes do metateatro. A ela pretendo, a seguir, apor a interpretação de Schmeling.

Manfred Schmeling publica, em 1982, Métathéâtre et intertexte, como versão revista e ampliada de um curso ministrado, em 1981, na Sorbonne. Já no prefácio ele anuncia sua intenção didática: não pretende fazer de seu trabalho um estudo exaustivo da história do teatro no teatro, nem uma análise puramente estrutural ou formalista. Pretende mostrar que a reflexão metadramática faz do texto uma espécie de história literária dramatizada e que o teatro que reflete o teatro também refletirá as transformações sofridas pela recepção do texto.

Sem fazer maior distinção entre as denominações théâtre dans le théâtre e jeu dans le jeu, sendo a última mais generalizante que a primeira, Schmeling constata que elas se reportam a um elemento comum, a que se pode chamar jeu drainatique à forme réfléchie, em que o caráter reflexivo aparece em níveis diferentes. É vasto o leque de suas manifestações: desde uma peça inteira intercalada dentro de outra peça até tematizações ou tomadas de consciência momentâneas da representação. O autor entende que as fronteiras entre esses dois 
extremos são por vezes difíceis de ser traçadas. A noção de "peça" implica uma relativa autonomia e uma certa integridade artística. Mas essa autonomia da representação intercalada quase não se encontra no teatro moderno. Em Esperando Godot, de Beckett, a "representação" se torna sujeito da peça, sem, contudo, constituir uma peça dentro da peça; já "O assassinato de Gonzaga", em Hamlet, é uma encenação completa de um drama no interior de outro drama mais vasto. Uma intriga secundária é incluída numa intriga primária. A noção de intriga pressupõe uma certa unidade dramática da representação teatral em segundo grau, e com o desaparecimento daquele conceito, em obras do teatro moderno, desaparece também a forma completa do teatro no teatro. O que se verifica é um discurso interrompido sobre o teatro antes de uma sequiência lógica e contínua de ações teatrais. Segundo Schmeling, quer se trate de teatro no teatro, quer de uma reflexão metateatral mais ou menos pontual, sempre encontraremos, pelo menos, dois níveis teatrais diferentes. Estruturalmente, este procedimento tem por objetivo levar o espectador a uma dupla perspectiva: o espectador real é o espectador primeiro, mas além disso ele assiste ao espetáculo a que também assiste o ator espectador de sua própria representação ou da representação de outros atores. De fato, há técnicas dramáticas que permitem a multiplicação do desdobramento ao infinito. Importa reconhecer que a técnica teatral do metateatro já era de uso no teatro jesuíta do século XVII e no Romantismo alemão. Não se entenda, portanto, que teatro no teatro seja uma invenção de Brecht ou de outros dramaturgos dos últimos tempos. A propósito, vejamos um breve extrato de Die verkehrte Welt $I O$ mundo às avessas], do romântico alemão Ludwig Tieck: "Vejam, camaradas, nós nos encontramos aqui como espectadores e assistimos a uma peça; dentro desta peça há espectadores assistindo a uma peça e, nessa terceira peça, os atores-espectadores acompanham uma outra peça." (apud Schmeling, op. cit., p.6)

A passagem nos mostra que ocorre uma representação na representação, não somente atualizada dramaticamente, mas ainda expandida por um texto que se aproxima da narração e que anuncia de antemão os procedimentos do palco, como no teatro épico de Brecht.

Se existe uma dupla relação entre representação e espectador, não quer dizer que se possa afirmar que o teatro no teatro signifique uma simples repetição da relação real entre ator e espectador. O relacionamento exterior entre o público e a peça é ontologicamente 
diferente do relacionamento interior entre o ator (enquanto espectador, ou seja, personagem consciente da representação) e a representação intercalada. Enquanto o espectador real tem suas reações livres, o ator transformado em espectador ou que reflete a representação é, ao contrário, determinado pelo texto. É claro, pois a forma de participação do espectador não pode ser pré-determinada pelo dramaturgo e se este tivesse tal pretensão, ela seria, necessariamente, parte da escritura da peça. Assim sendo, o público verdadeiro nunca se submeterá à ficção teatral como o público no interior da peça.

Expostas essas reflexões sobre os constituintes do teatro no teatro, entende Schmeling que se pode proceder a uma definição:

[...] pode-se dizer que o teatro no teatro, em sua forma ideal, é um elemento intercalado num drama, que dispõe de seu espaço cênico próprio e de sua própria cronologia - de tal modo que se estabelece uma simultaneidade espacial e temporal da esfera cênica e dramatúrgica. (Schmeling, 1982, p.7-8)

Lembrando que o teatro no teatro apresenta numerosos elementos constituintes que reproduzem os do elenco, a representação em segundo grau terá lógica e freqüientemente uma subordinação semântica ao quadro dramático dado, ou seja, ocorre a repetição de uma forma artística. Entende Schmeling que se deva reservar a expressão "teatro no teatro" àquelas peças em que o teatro será tematizado enquanto meio artístico.

Passo seguinte, na exposição do pensamento de Schmeling, será a formulação de alguns princípios teóricos sobre teatro no teatro. O estudioso sugere não só que a representação na representação conforma uma técnica particular, mas também que a aparição dessa forma poderia estar ligada a um certo desenvolvimento histórico da literatura em geral. Assim:

- O teatro no teatro constitui uma espécie de história literária no interior da obra, porque comporta crítica ou julgamento de um passado literário em geral e das condições de produção e recepção do gênero em particular: é uma literatura em confronto;

- O teatro no teatro liga-se freqüentemente à paródia, uma forma de confrontação marcada como antiteatro por oposição ao teatro burguês. Isso ocorre quando a tradição literária se mostra por 
demais canônica, aborrecida e sobrepujada pela evolução extraliterária (econômica, social etc.). Para explicar essa historicidade interna do teatro auto-reflexivo ou auto-temático, Schmeling agrega a fórmula de Edward Balzercan, crítico na tradição do formalismo russo:

Face à literatura, o auto-tematismo tem a mesma atitude que a literatura não auto-temática face à língua corrente: ela não respeita suas regras. Todas as vezes que em determinado período da história literária aparece uma produção auto-temática, é porque os sistemas existentes e codificados da comunicação literária no processo de interação social são decorrentes da "língua corrente" - e porque esse fenômeno tornouse consciente. (Schmeling, op. cit., p.9)

- Historicamente falando, o teatro no teatro esbarra em limites que não pode ultrapassar. São limites fixados por uma consciência estética, fundados sobre normas restritivas de um teatro bem feito, como no caso de três importantes correntes da história literária: a clássica do século XVIİ, o racionalismo do século XVIII e o realismo/naturalismo da segunda metade do século XIX.

Propondo uma morfologia mais detalhada das variantes deste teatro, Schmeling diferencia formas completas de formas periféricas de teatro no teatro. Entre as primeiras distinguem-se as seguintes categorias:

- Peças em que os atores fictivos da representação intercalada não são idênticos aos atores reais;

- Peças em que os protagonistas do teatro no teatro são idênticos aos protagonistas do teatro no primeiro nível;

- Peças com protagonistas total ou parcialmente idênticos nos dois níveis teatrais. Esta terceira categoria, contudo, distingue-se da anterior pelo fato de produzir um resvalo permanente de um nível ao outro. Assim, o público real se vê confrontado com um problema de identificação concernente à relação entre a realidade interna ou fictiva e a divisão dessa realidade em simulacro. Procedimento desta natureza adota Pirandello em Sei personnaggi in cerca d'autore para exprimir a alienação do mundo: realidade e ilusão já não são mais categorias com significados fixos. Essa 
técnica de mistura já vem dos séculos dezesseis e dezessete, com a diferença de que então a concepção barroca de theatrum mundi era ligada a valores religiosos, em especial ao dogma da graça, que afirmava haver, malgrado a existência da aparência e da vaidade no interior da vida real, uma realidade superior, uma verdade celeste;

- Peças em moldura fechada, em que a representação começa e acaba no primeiro nível teatral;

- Peças de moldura aberta, em que a representação começa no primeiro nível e acaba no segundo ou vice-versa;

- Peças em que o teatro no teatro constitui um lugar teatral separado, e

- Peças com um lugar teatral comum aos diferentes níveis da representação.

Às formas completas de teatro no teatro ajuntam-se outras, periféricas, que podem apoiar as estruturas descritas acima, mas que também podem ocorrer freqüentemente independentes delas. Essas formas periféricas não constituem um teatro no teatro propriamente dito; carregam, contudo, um acentuado caráter metateatral. Vejamos:

- O prólogo ou representação preliminar reporta-se diretamente à enfabulação da peça, como em muitas obras brechtianas, por exemplo, A resistivel ascenção de Aurturo Ui, ou abre simplesmente o espaço teatral, como em Fausto, de Goethe;

- O epílogo, como o prólogo, constitui uma reflexão sobre a representação, mas aqui a posteriori: o espectador não deixa a sala sob a impressão direta da ilusão. Sirva como exemplo A alma boa de Setsuan, de Bertolt Brecht, como veremos adiante;

- A fala ao público é empregada sobretudo por razões didáticas: ele é convocado a considerar o que lhe diz o ator. Em casos extremos, como em Publikumsbeschimpfung [Insulto ao público] de Peter Handke, toda a peça pode se constituir unicamente de um discurso aos espectadores;

- O coro comenta a representação, o que não deve ser confundido com uma tomada de consciência do teatro enquanto tal. Na tragédia clássica, o coro comentava o significado e não o significante. No teatro moderno, o coro provoca frequientemente uma reflexão sobre os constituintes teatrais. Em obras de Brecht, 
canções assumem o papel do coro e até mesmo a função de personagem, como na peça didática $A$ decisão;

- Com saída do papel procede-se à quebra da ilusão. A comédia romântica alemã nos mostra de que modo essa perda da unidade do papel se liga à forma do teatro no teatro. Ludwig Tieck, em Der gestiefelte Kater [ $O$ gato de botas], adota esta técnica ao excesso, a ponto de quase impedir que, naquela peça, o teatro no teatro se concretize;

- Uma outra forma periférica de teatro no teatro é a didascália chamada à parte. Com ela cria o dramaturgo uma certa distância em face da representação. $\mathrm{O}$ ator, ao falar à parte, dirige-se ao espectador de forma indireta, convidando-o ao riso, à reflexão etc., $\mathrm{e}$

- Com o meneur de jeu, o que dirige o teatro no teatro, introduz-se um mediador que instaura uma instância entre a esfera da produção e a da recepção: é o lado semântico. O mediador convida-nos a refletir sobre o conteúdo da peça. Ao mesmo tempo, essa mediação significa um distanciamento: é o lado estético. Na tradição do teatro épico brechtiano, a distância estética é condição necessária para uma atitude crítica diante dos problemas tratados em cena. Um bom exemplo de meneur de jeu, dentro da produção teatral de Brecht, é o cantor em $O$ círculo de giz caucasiano.

Schmeling não procura critérios de classificação no interior dos gêneros dramáticos mas na relação com o nível de discurso. Ele estabelece oposição entre discurso dramático e discurso metadramático. Com o teatro no teatro instala-se, com efeito, uma dimensão narrativa à medida que a representação em segundo nível é perspectivada por uma autoridade estética e crítica que não pode ser outra que a do próprio autor. Isto vale sobretudo para peças em que a representação interna - pode ser mais de uma - possui uma função parabólica, como em $O$ Círculo de giz caucasiano. Aí não se formula tese, nem moral. A intriga não mais se entende como mimesis da tragédia clássica ou do drama naturalista, mas como um arranjo artificial. O espectador está consciente de que os protagonistas não agem e não falam por eles mesmos. O deus ex machina, o que faz agir e falar, está presente em cena, representado pelo "cantor". É importante notar que, mesmo havendo coincidência técnica entre as formas do teatro no teatro e as do teatro épico de Brecht, sempre 
citado como exemplo, elas não têm necessáriamente a mesma função.

Nesse contexto, é interessante agregar o pensamento de Anne Ubersfeld, para corroborar sobretudo o de Schmeling. Em seu livro L'école du spectateur, publicado em 1981, ao estudar o espaço-teatro, indaga do teatro no teatro, e assim o define: "Ocorre teatro no teatro quando há dois espaços embutidos, onde um é representação para o outro. É necessário, pois, que haja observadores e observados, mesmo se uns e outros sejam observados pelo público." (Ubersfeld, 1981, p.111)

Entendo que ela quer dizer que, seja no palco, seja na platéia, deverá ocorrer a conscientização - no ator-espectador ou no espectador efetivo, ou mesmo em ambos -, de que se está no teatro e seus signos não têm valor de verdade, a não ser enquanto encenação. Assim, cada vez que o espaço cênico produz essa sensação de quebra, sempre que se explicite um espetáculo dentro da encenação, teremos uma dupla funcionalidade: a da revelação do real e a afirmação da teatralidade. Contudo, não é necessário que se tenha dois espaços reais e realmente distintos no palco, em que um exerça a função de teatro para o outro; basta que alguns signos teatrais se imponham em alguns atores presentes em cena para que se possa falar de teatro no teatro.

Ubersfeld ensina que as personagens devem demonstrar indícios de teatralidade, de desempenho de um papel, para que possam ser acolhidos como elementos pertinentes ao estudo do metateatro. Nesse sentido, por exemplo, os indícios de teatralidade em Don Juan de Molière levam em conta que freqüentemente Don Juan fala e age por Sganarelle, enquanto espectador. A presença desse espectador privilegiado teatraliza Don Juan. A propósito desta recorrência nas peças teatrais de Bertolt Brecht, Ubersfeld diz: "Cada vez que um ato de bravura de uma personagem faz teatro aos olhos das outras personagens, temos, por um momento, a estrutura provisória, por vezes fugaz, de um espaço-teatro. " (Ubersfeld, op. cit., p.115)

Quanto à teatralização da personagem, a autora chama a atenção do leitor para o fato de aquela não ter existência concreta enquanto desprovida de representação concreta; quer dizer, a pesonagem textual é apenas uma personagem virtual, que aguarda a presença física do ator para sofrer modificações que este lhe conferirá. No entanto, a teatralização da personagem, que é fruto de elementos concretos da representação, já vem marcada textualmente em um 
grande número de casos. Textualmente a personagem pode ser teatralizada:

- por sua fala teatralizante, ou seja, por apresentar-se diretamente ao público. É o que se encontra já no prólogo de $A$ alma boa de Setsuan: de um lado, a própria didascália o exige (Wang. aguadeiro da cidade, apresenta-se ao público), e de outro lado, a fala do ator demonstra o papel que desempenhará (Eu sou vendedor de água, aqui na capital de Setsuan);

- pela máscara teatral que ela veste. Ubersfeld entende aqui máscara não como aquela, concreta, da representação antiga ou da comédia de arte ou, ainda, do teatro japonês, mas como o nome, ou seja, personagem já conhecida através da lenda ou da história e teatralizada por sua simples menção. Galileu, as personagens de Antígona, e as de A vida de Eduardo II da Inglaterra, entre tantas personagens criadas por Brecht, preenchem estes requisitos;

- pela máscara de identidade emprestada, da qual o espectador conhece o segredo. A prostituta chinesa Chen Te, de Brecht, revela ao público a identidade que assume e

- pela identidade que se mantem problemática. De certa maneira, Galileu, e Chen Te, para continuar com exemplos de personagens já citadas - encobrem total ou parcialmente suas identidades, conferindo-lhes uma problematicidade a ser aclarada pelo espectador. Ubersfeld entende que a teatralização da personagem não é recurso exclusivo do metateatro, mas ressalta que é típico deste:

Sem falar exatamente do funcionamento daquilo que se convencionou chamar de teatro no teatro, um bom número de personagens é objeto de uma teatralização fundadora: todo o teatro de Jean Genet repousa sobre essa transformação das personagens em papéis; provavelmente é este modo de escrever que torna o objeto literário moderno o mais "teatral" possível. Os grandes "heróis"de teatro são teatralizados por si mesmos, se é que se pode dizer assim, ou pelos outros protagonistas. (Ubersfeld, 1982, p.137) 
O entendimento da questão do metateatro por Abel, Schmeling e Ubersfeld poúem configurar recursos não tanto para mostrar a utilidade de análises relativamente difíceis, mas sim para indicar as possibilidades imensas à disposição daqueles que praticam a representação da realidade no lugar particularmente apropriado, chamado teatro.

\section{Referências Bibliográficas}

ABEL, Lionel. Metateatro: uma visão nova da forma dramática. Trad. Bárbara Heliodora. Rio de Janeiro: Zahar Editores, 1968.

BARTHES, Roland. Crítica e Verdade. São Paulo: Editora Perspectiva, 1970.

BRECHT, Bertolt, 1898-1956. Teatro completo, em 12 volumes. Rio de Janeiro: Paz e Terra, 1992 - (Coleção teatro; v.1-12).

FERREIRA, Aurélio Buarque de Holanda. Novo Dicionário da Lingua Portuguesa. Rio de Janeiro: Nova Fronteira, 1975.

HECHT, Werner (Hrsg.) Bertolt Brecht: Arbeitsjournal. Frankfurt am Main: Suhrkamp, 1973.

KLUGE, Gerhard. Werkimmanente Poetik in zwei Stücken von Tankred Dorst und Martin Walser oder Wie man das Spiel nach Brecht spielt. In: AMSTERDAMER Beiträge zur neueren Germanistik. Amsterdam: Rodopi, 1983. v. 16, p. 69-88.

SCHMELING, Manfred. métathéâtre et intertexte. aspects du théâtre dans le théâtre. Paris: Éditions Lettres Modernes, 1982. (Archives de lettres modernes 204).

UBERSFELD, Anne. L'école du spectateur. Paris: Les Éditions sociales, 1981.

UBERSFELD, Anne. Lire le Théâtre. Paris: Éditions sociales, 1982. 